\title{
Gastrostomy and mechanical ventilation in amyotrophic lateral sclerosis: how best to support the decision-making process?
}

\author{
Krzysztof Barć ${ }^{1}$, Magdalena Kuźma-Kozakiewicz ${ }^{1,2,3}$ \\ ${ }^{1}$ Department of Neurology, University Clinical Centre of Medical University of Warsaw, Warsaw, Poland \\ ${ }^{2}$ Department of Neurology, Medical University of Warsaw, Warsaw, Poland \\ ${ }^{3}$ Neurodegenerative Diseases Research Group, Medical University of Warsaw, Warsaw, Poland
}

\begin{abstract}
The unfavourable outcome of amyotrophic lateral sclerosis (ALS) confronts patients with challenging decisions regarding life-sustaining measures. The decision-making process is usually triggered by medical consultations and patient-dependent factors. This may largely depend on the physician's depth of knowledge and professional experience.

This paper presents an overview of the life-sustaining methods used in ALS and their effects on disease progression, survival and quality of life of patients and their caregivers. It is intended to aid physicians in their discussions with patients. We interrogate all the positive and negative facets of life-sustaining measures that may allow for optimisation of the decision-making process and care provision.
\end{abstract}

Key words: amyotrophic lateral sclerosis, therapeutic strategies, gastrostomy, mechanical ventilation, quality of life, survival (Neurol Neurochir Pol 2020; 54 (5): 366-377)

\section{Introduction}

Amyotrophic lateral sclerosis (ALS) is a devastating neurodegenerative disease primarily involving the motor neuron cells in the brain and spinal cord. It is clinically characterised by muscle weakness and wasting which leads to quadriparesis, usually accompanied by impairments of speech and swallowing. Respiratory failure, which develops over the course of the disease, leads to death within 2-5 years of initial symptoms onset [1].

There are only two registered drugs to modify survival (riluzole) and disease progression (edaravone, but only in a subgroup of patients). Thus, most ALS patients require the support of medical devices at advanced stages, including percutaneous endoscopic or radiologically inserted gastrostomy (PEG/RIG), non-invasive (NIV) or invasive ventilation (IV) [2]. These methods may affect patients' physical and psychological integrity. The decision-making process reflects several factors including the patient's personal values, relations with caregivers, social support, economic situation, and a feeling of being a burden to one's family $[3,4,5]$. To ensure the provision of satisfactory care, the discussion during medical consultation should focus on the benefits, risks, constraints, and consequences of each life-sustaining method.

Beside halting disease progression and prolonging life, the fundamental goal of the management of ALS is to maintain or improve quality of life (QoL) [6]. According to the World Health Organisation (WHO), QoL comprises health-related factors such as physical, functional, emotional, and mental well-being, as well as non-health-related factors such as jobs, family, friends, and spirituality $[7,8]$. Although almost twothirds of ALS patients declare 'health' to be a relevant domain of their QoL, the self-generated ratings describe a range of categories beyond physical and functional impairment [9]. These include the support of caregivers as well as existential and psychological factors [9-14]. Moreover, despite the relentless progression of physical disabilities, no significant correlation between functional performance and QoL has been found in patients with ALS $[4,9-11,15,16]$. Thus, non-health-related factors appear to play an important role in determining an ALS patient's well-being. 
In this paper, we summarise the literature on the use of gastrostomy, NIV and IV in ALS patients with respect to each treatment's impact on disease progression, survival, and overall QoL of ALS patients and caregivers. Our aim is to aid physicians in their discussions with patients. We believe that thorough discussion of the positive and negative aspects of life-sustaining measures will allow for optimisation of the decision-making process and care provision.

\section{Enteral nutrition}

\section{Weight loss in ALS}

Weight loss is a common feature in ALS, seen in c. 16-56\% of patients $[17,18,19]$. It is not solely attributable to dysphagia, as symptoms of impaired swallowing are absent in $40 \%$ of malnourished patients [17]. Higher energy expenditure results from increased respiratory effort, muscle fasciculation, hypermetabolism, decreased food intake caused by a loss of appetite, hypogeusia, fatigue, depression, inadequate caloric intake, and constipation due to decreased physical activity [17, 20-22]. Malnourishment itself further induces skeletal muscle wasting, fatigue, and an altered pattern of muscle contraction and relaxation [23, 24]. All of these affect QoL, which may further impair food intake and loss of weight in a 'vicious cycle' [23].

\section{Indication and methods}

The primary management of dysphagia involves support techniques, including a correct upright eating position, adjusting dentures, thickening of liquids and blending/softening of solid foods, along with providing small, high-calorie, frequent meals $[6,25]$. Enteral tube nutrition should be considered if weight continues to decrease despite these measures.

The procedures include a percutaneous endoscopic gastrostomy (PEG) and a percutaneous radiologic gastrostomy (PRG), also known as a radiologically inserted G-tube. A nasogastric tube is an option only for a short period because it is uncomfortable and can lead to oesophageal ulcers $[25,26]$. Determining the optimal time for starting enteral nutrition is challenging. Physicians should consider both the nutritional and respiratory status of the patient. Symptomatic dysphagia, dehydration, prolonged or curtailed meals due to choking, a BMI of $<18-18.5$ or a loss of weight of more than $10 \%$ or even as little as $5 \%$ of the premorbid value indicate the need for enteral tube feeding (PEG or PRG) in ALS patients $[19,25$, $27,28]$. The objective is also to minimise the risk of perioperative complications (i.e. aspiration pneumonia or respiratory insufficiency). Therefore, it is recommended to perform the procedure when the predicted FVC value is still $>50 \%[25$, 29,30]. Although a lower FVC is not a contraindication for PEG/RIG, the procedure should be performed with caution $[25,29]$. For a summary of indications for gastrostomy tube feeding, see Table 1.
Table 1. Indications for PEG administration in patients with ALS

\begin{tabular}{|c|c|c|}
\hline & Indications & References \\
\hline Clinical symptoms & $\begin{array}{l}\text { Symptomatic dysp- } \\
\text { hagia, dehydration, } \\
\text { ending meals } \\
\text { prematurely because } \\
\text { of choking, frequent } \\
\text { pulmonary infection }\end{array}$ & 25 \\
\hline \multicolumn{3}{|l|}{ Nutritional status } \\
\hline BMI & $<18.5 \mathrm{~kg} / \mathrm{m}^{2}$ & 19 \\
\hline Weight loss & $>5-10 \%$ & 25,27 \\
\hline \multicolumn{3}{|l|}{ Respiratory status } \\
\hline Saturation & $\begin{array}{l}\geq 6 \text { dips in arterial } \\
\text { saturation }<90 \% \text { per } \\
\text { hour }\end{array}$ & 35 \\
\hline $\mathrm{PaCO}_{2}$ & $<40 \mathrm{mmHg}$ & 29,35 \\
\hline FVC & $>50 \%$ & $19,25,29$ \\
\hline
\end{tabular}

BMI - Body Mass Index; FVC — Forced Vital Capacity

In ALS patients, $\mathrm{PEG}$ is used more widely than other methods for enteral feeding [27]. PRG was initially recommended in patients with slow vital capacity $<50 \%$ due to a higher success rate and a lower rate of major complications [31, 32, 33, 34]. Further studies (by Shaw et al. and the ProGas study) have shown a comparable safety profile between PEG and PRG [27, $35,36]$. In order to increase safety, the use of NIV before or during the procedure should be considered if PEG insertion is planned in patients with respiratory symptoms $[37,38]$. Except for pain at the site of gastrostomy (more common in patients undergoing PEG), there are no significant postoperative differences between the RIG and PEG methods [39]. Generally, the choice of method of enteral tube feeding should be based on the experience of a local centre $[6,25]$.

Due to the more frequent use of PEG than of PRG in ALS patients, further topics are discussed below based on the literature concerning PEG.

\section{Provision of PEG}

The provision of enteral nutrition depends on the healthcare system [40]. An analysis of both sociodemographic and disease indicators in a group of 121 patients showed that a baseline preference for PEG was the strongest predictor for later opting for this measure [41]. In addition, discussing PEG with a clinician experienced in the field of nutrition significantly increases patients' positive decision rate regarding PEG insertion [42]. A similar effect is seen in patients following a meeting with a professional home care team $[3,43]$.

\section{Effect of PEG on weight and survival}

Loss of weight and a low BMI are well-known predictors of shorter survival in ALS $[17,18,44,45,46]$. The risk of death is 3.5 to 7.7 -fold higher in malnourished ALS patients [18, 
19]. Numerous reports have shown that patients with $P E G$ maintain, or even increase, their total body weight $[17,19,28$, $30,42,47,48,49]$. This is especially important because there is evidence of slower disease progression in individuals with a BMI of 30-35 [46, 50, 51].

Mean survival following PEG insertion ranges between 122 and 393 days. The mortality rates are below $3.6 \%$ and $11.5 \%$ at 24 hours and 30 days, respectively [28, 30, 52, 53]. Forbes reported survival rates of $46 \%$ (39\% for limb-onset and $51 \%$ for bulbar-onset) and 23\% (17\% for limb-onset and 27\% for bulbar onset) six months and 12 months after the procedure, respectively [54]. Although there is no difference in survival among patients according to the use of PEG or RIG, patients on nasogastric tube feeding demonstrate significantly shorter survival $[32,35,39]$.

PEG does not prevent aspiration. Risk factors for aspiration during PEG include previously experienced aspiration pneumonia, evidence of reflux oesophagitis at the time of endoscopy, older age, male gender, diabetes, and the presence of infection [30].

Multiple studies have investigated an association between the $\mathrm{FVC} \%$ at the time of PEG insertion and the post-PEG survival time. The implementation of PEG results in a longer survival in ALS patients as long as the FVC exceeds 38\% of the predicted value [29]. Most studies have reported a significantly longer survival in patients with FVC $>50 \%$ compared to FVC $<50 \%$ of the predicted value $[28,30,55]$. However, both groups showed longer survival when compared to patients who refused PEG placement [28]. Two publications have reported a longer post-PEG survival in patients with $\mathrm{FVC}$ of $65-70 \%$ of predicted value compared to FVC of $50-65 \%$ [47, 56]. Death within 30 days following PEG introduction has also been reported to occur more commonly in patients with a decreased predicted volume of FVC $(<50 \%)$ and decreased serum chloride [30].

Determinants of a poor late outcome of PEG include an initial weight loss of over $10 \%$, a decreased predicted value of FVC $(<50-70 \%)$, BMI $\left(<18 \mathrm{~kg} / \mathrm{m}^{2}\right)$, long-lasting swallowing difficulties prior to the start of PEG, older age, a low bulbar score of ALSFRS-R $(\leq 5)$, and concomitant neurobehavioural dysfunction [19, 28, 29, 30, 42, 43, 47, 54, 56-59]. Studies on the effect of gender have proved inconclusive $[29,42,60]$.

Although some reports fail to show a survival benefit, they could be biased by methodological issues. A large population-based study from Scotland compared 142 PEG patients to 1,084 non-PEG patients, and found no difference in the median survival between the two groups. However, in this cohort, the PEG group was characterised by a significantly shorter diagnosis delay (a well-known predictor of poor outcome in ALS), that was not included in the regression model [54]. One study reported an even shorter survival time in the PEG group, but the control group consisted of individuals who declined the use of PEG as well as some who had no indication for parenteral feeding [28]. In a meta-analysis $(n=966)$ using an odds ratio (OD) as the survival rate, a higher mortality in patients without PEG compared to the PEG group was found only at the 20-month follow-up $(\mathrm{OR}=1.97 ; 95 \%$ CI 1.21-3.21, $\mathrm{p}=0.007$ ); there was no significant difference in the 30-day or 30-month rates [61].

A major limitation of studies investigating the effect of PEG on survival in ALS patients is the methodological difficulty. A comparison can only be made with patients who refused PEG, with the result that no nutritional surveillance was provided for them, or with patients for whom there was no indication of PEG, who thus primarily represented a group with better outcomes.

\section{Effect of PEG on QoL}

Weight loss in patients with ALS is associated with a worse self-reported QoL and shows a trend towards a decreased mood [17]. In particular, the Vitality domain of SF-36, reflecting exhaustion, tiredness and lack of spirit, has been found to strongly relate to weight loss in ALS patients [17].

Surprisingly, only a few studies have explored the effect of PEG on QoL in ALS. Mazzini et al. found that patients declared an improvement in QoL and better integration into social and family environments following PEG insertion; however, the paper provided no data [28]. Zamietra et al reported a slight, insignificant decrease in QoL following PEG insertion in patients without concurrent use of NIV $(\mathrm{n}=11)$; they maintained this score in subjects with concurrent use of NIV $(n=5)$ [62]. In a study involving 13 patients, 11 (85\%) individuals declared an improved QoL following PEG insertion, but no patient reported deterioration in QoL [17]. Moreover, among individuals in a locked-in state, $90 \%$ would opt for PEG placement again [16]. Mathus-Vliegen et al. found that frequent choking on food and drink significantly impaired QoL of patients without PEG compared to those using PEG [52].

\section{Effect of PEG on disease progression}

There is no evidence showing that PEG alters disease progression in ALS patients. Specifically, Kasarskis et al. reported no effect on ALSFRS-R speech, swallowing, salivation, or total score deterioration following PEG insertion [30]. Nor was there any effect detected on FVC or SIP [30]. In a sixmonth follow-up study, patients using PEG maintained their ALSFRS-R score (pre $34.1 \pm 8.6 v s$ post $34.8 \pm 7.4, \mathrm{p}>0.05$ ), while those without PEG noted a slight drop (33.7 \pm 7.9 vs $31.6 \pm 8.8, \mathrm{p}>0.05)$ [42].

\section{Impact of PEG on caregivers}

There is a comparable mean burden for caregivers who care for patients with or without PEG $(n=328)$ [43]. Traila et al. reported a similar attitude towards the placement of PEG between patients and caregivers: $52 \%$ of patients and $58 \%$ of caregivers endorsed the idea of future PEG placement, 22\% of patients and $10 \%$ of caregivers were uncertain, and $26 \%$ of patients and $32 \%$ of caregivers responded negatively [63]. 
Table 2. Indications for NIV administration in patients with ALS

\begin{tabular}{|c|c|c|c|c|}
\hline & AAN 2009 & EFNS 2012 & NICE 2016 & References \\
\hline Clinical assessment & $\begin{array}{l}\text { Symptoms and signs of respi- } \\
\text { ratory insufficiency }\end{array}$ & $\begin{array}{l}\text { Symptoms and signs of respi- } \\
\text { ratory insufficiency }\end{array}$ & $\begin{array}{l}\text { Symptoms and signs of respi- } \\
\text { ratory insufficiency }{ }^{1}\end{array}$ & $\begin{array}{c}25,70,88,129,130, \\
131,132\end{array}$ \\
\hline FVC & $<50 \%$ & $\begin{array}{c}<80 \% \\
+ \\
\text { Symptoms and signs of respi- } \\
\text { ratory insufficiency }\end{array}$ & $<50 \%$ & $66,67,68,70,133$ \\
\hline $\begin{array}{l}\text { Abnormal nocturnal } \\
\text { oximetry }\end{array}$ & Yes $^{2}$ & $Y_{e s}^{2}$ & - & $71,84,132$ \\
\hline SNIP & $<40 \mathrm{~cm} \mathrm{H}_{2} \mathrm{O}$ & $<40 \mathrm{~cm} \mathrm{H}_{2} \mathrm{O}$ & $<40 \mathrm{~cm} \mathrm{H}_{2} \mathrm{O}$ & 133 \\
\hline MIP & $<60 \mathrm{~cm} \mathrm{H}_{2} 0$ & $<60 \mathrm{~cm} \mathrm{H}_{2} \mathrm{O}$ & $<40 \mathrm{~cm} \mathrm{H}_{2} \mathrm{O}$ & 70,71 \\
\hline $\mathrm{ABG} \mathrm{PaCO}_{2}$ & - & $>45 \mathrm{~mm} \mathrm{Hg}$ & $>45 \mathrm{~mm} \mathrm{Hg}$ & 70 \\
\hline $\begin{array}{l}\text { SNIP or MIP (+ symptoms } \\
\text { and signs of respiratory } \\
\text { insufficiency }{ }^{1} \text { ) }\end{array}$ & - & - & $\begin{array}{l}\hat{O}<65 \mathrm{~cm} \mathrm{H}_{2} \mathrm{O} \\
q<55 \mathrm{~cm} \mathrm{H}_{2} \mathrm{O}\end{array}$ & \\
\hline
\end{tabular}

AAN - American Academy of Neurology; EFNS — European Federation of Neurological Societies; NICE — National Institute for Health and Clinical Excellence; FVC — forced vital capacity; SNIP — sniff nasalinspiratory pressure; $\mathrm{MIP}$ - maximal inspiratory pressure; $\mathrm{ABG} \mathrm{PaCO}_{2}$ - arterial blood gas

'symptoms: daytime sleepiness, dyspnoea, orthopnoea, frequent awakening, morning headaches, daytime fatigue; signs: tachypnoea, use of auxiliary respiratory muscles, paradoxical movement of the abdomen, decreased chest wall movement, weak cough, sweating, tachycardia, morning confusion, hallucinations, weight loss, mouth dryness.

${ }^{2}$ oxygen saturations of less than $90 \%$ for 1 cumulative minute; 15 periods of oxygen desaturation per hour; oxygen saturations of less than or equal to $88 \%$ for 5 consecutive minutes

Therefore, it is advisable to discuss the need for PEG/PRG insertion with both the patient and their caregiver, to facilitate the decision process.

\section{Non-invasive ventilation (NIV)}

Although respiratory insufficiency is the initial manifestation of the disease in only $2-3 \%$ of cases [64], it remains the most frequent cause of death in patients with ALS [65]. Breathing failure directly results from inspiratory and expiratory muscle weakness, but it may also be due to bulbar dysfunction accompanied by aspiration and/or airway obstruction. Importantly, breathlessness remains a significant source of distress to patients with ALS (comparable to pain). Hypoventilation leads to sleep disturbances, morning headaches, and fatigue. Thus, the use of NIV goes beyond the support of respiratory functions: it is a means of pain relief and an effective treatment for hypoventilation-induced symptoms.

Overall, the introduction of NIV in ALS is recommended when the FVC is less than $50 \%$ of the predicted value, or less than $80 \%$ in the presence of signs and symptoms of respiratory insufficiency $[25,66-70]$. It is important to remember that the FVC volume is even lower in the supine position (by as much as $11 \%)[71,72]$. Blood gas measurements may be helpful in the evaluation of respiratory function in an ALS patient, although gas exchange may be well preserved even when the FVC decreases to $20 \%$ of the predicted value [73]. Measuring morning arterial blood gases is especially valuable in individuals with bulbar involvement, in whom spirometry encounters technical challenges [25]. A summary of indications for NIV is presented in Table 2 .

The use of NIV is characterised by a 'threshold effect', wherein there is a significant reduction in $\mathrm{PaCO}_{2}$ only when the use of NIV exceeds four hours per night [74]. Above this threshold, there is a dose-dependent effect on gas measurement [74]. Patients with poor adherence, or poor ventilation, do not benefit from NIV in any way, and thus a strict follow-up prior to discharge of the patient is required to ensure whether the patient uses the device properly and for the correct amount of time [75]. Such compliance is achieved in 49-72\% of individuals with ALS $[68,76,77]$. The risk of intolerance is increased in patients with moderate or severe bulbar symptoms, in individuals with low predicted FVC at NIV initiation, and in patients with symptoms of cognitive or behavioural impairment $[57,68,76,77]$.

Despite this, NIV should be introduced to all patients with ALS and respiratory insufficiency because there is no study that proves that patients with either onset would definitively fail to benefit from non-invasive respiratory support [EAN guidelines, in preparation]. No effect of age, gender, or disease duration has been found [76, 77].

According to the literature, the implementation of NIV can be performed either in a hospital setting or an outpatient clinic, with a comparable frequency of adverse events and comparable lengths of stay $[78,79]$. Although it differs according to the healthcare system, NIV initiation at the outpatient clinic allows for a significant reduction in the waiting time before NIV implementation (13.5 vs 30 days for out- and in-patients, respectively, $\mathrm{p}=0.04)$ [78].

\section{Effect of NIV on survival}

In a randomised study of patients with orthopnoea and PI $\max <60 \%$ of the predicted value or symptomatic daytime hypercapnia, 22 patients assigned to NIV showed a significantly higher survival rate $(\mathrm{p}=0.0062)$ relative to 19 patients assigned to standard care [80]. Detailed analysis revealed that 
the significant effect was found in patients with normal or moderately impaired bulbar function $(p=0.0059)$ but not in the case of severe bulbar dysfunction $(p=0.92)$ [80]. In a group of patients with bulbar ALS, Pinto et al. reported improved one-year (100\% vs $88.9 \%)$ and three-year survival $(87.5 \%$ vs $22.2 \%)$ in patients with diurnal abnormalities in gas exchange with NIV $(\mathrm{n}=10)$ compared to those without NIV $(\mathrm{n}=10)$ [81]. There is no strong evidence for an impact of the site of onset on the outcome of NIV, except for patients with severe bulbar impairment [80-82].

Lechtzin et al. showed that early implementation of NIV in ALS patients ( $\geq 65 \%$ of predicted FVC) resulted in longer survival and longer time to tracheostomy from diagnosis compared to patients qualified to NIV at $<65 \%$ of predicted FVC (2.7 years $v s 1.8$ years, $\mathrm{p}=0.045$ ) [83]. In another study, the time to NIV implementation correlated inversely to survival with NIV $(r=-0.65, p<0.001)$ [84]. These results show that the early use of NIV increases survival in ALS patients. This may be partly due to a greater compliance as achieved at the initial stage of respiratory insufficiency [84].

A combination of NIV and PEG shows a trend towards longer survival in ALS patients compared to one or the other applied alone (HR: $0.34,95 \%$ CI $0.10-1.14, p=0.08$ for NIV-alone; HR: $0.51,95 \%$ CI 0.21-1.26, $\mathrm{p}=0.15$ for PEG-alone) [82]. However, this needs to be confirmed in further studies, because Zamietra et al. found the same rate of ALSFRS-r deterioration in a small group of ALS patients who used PEG alone $(n=11)$, NIV alone $(n=6)$, and PEG and NIV combined $(n=5)$ [62].

Although there is no difference in the prevalence of NIV between patients with and without neurobehavioural dysfunction, the presence of the latter results in reduced survival, mainly due to poorer compliance [57].

\section{Effect of NIV on quality of life}

Respiratory muscle weakness has a significant influence on both sleep-related and non-sleep-related domains of the QoL in ALS patients. It shows a greater impact than the overall severity of the disease $[85,86]$.

The positive effect of NIV on the QoL in ALS patients has been reported in multiple studies. In an up-to-12-month follow-up randomised study (NIV vs normal care), an improvement in the mental component via SF-36 analysis (of mild to moderate bulbar-impaired patients) was observed along with the symptoms domain of sleep apnoea quality-of-life index (SAQLI) (of all patients) [80]. In addition, the improvement in health-related QoL (HRQoL) was associated with the use of NIV, reaching its peak 3-5 months after the introduction of respiratory treatment [80]. In agreement with these findings, another study reported an improvement in Epworth Sleepiness ( $p<0.001)$, McGill Quality of Life Questionnaire (McGILL QOL) ( $\mathrm{p}<0.001)$, SAQLI ( $<<0.001)$, Chronic Respiratory Disease Questionnaire (CRDQ) - Fatigue ( $<<0.001)$, Emotional $(\mathrm{p}<0.01)$, Mastery $(\mathrm{p}<0.01)$, and SF-36 - Mental
Health $(\mathrm{p}<0.05)$, and Vitality $(\mathrm{p}<0.01)$ scores with respect to use of NIV at 9 months of follow-up [85]. In a prospective 6-week study, Newsom-Davis et al. noted an improvement in cognitive functions and no deterioration of anxiety or depression measures in a group of nine ALS patients following the start of NIV [87].

\section{Effect of NIV on disease progression}

There is no evidence that NIV affects overall disease progression, as measured by the rate of ALS-FRS-r deterioration, or respiratory muscle weakness (RMW) progression [71, 81, 85]. However, a slower decline in lung function seems to occur with the use of NIV in ALS patients. In particular, four studies have shown a decrease of the VC from $2.52 \%$ to $1.09 \%, 4.8 \%$ to $3.5 \%, 2.92 \%$ to $0.5 \%$, and $5.1 \%$ to $2.5 \%$ per month, respectively $[68,88-90]$. The mechanism is unclear but is possibly related to an increased pulmonary and chest wall compliance along the NIV use [85]. These findings must be treated with caution, because a slower decrease of FVC has also been reported in patients without NIV after their FVC values decreased below $55 \%$ of the predicted value [91].

\section{Impact of NIV on caregivers}

Mustfa et al. showed that caregivers of NIV patients $(n=21)$ had similar increase in burden than did caregivers of patients without indication for NIV $(n=10)$ [85].

\section{Invasive ventilation (IV)}

Patients require invasive ventilation once the need for NIV exceeds $23 / 24 \mathrm{~h}$ or in a case of abundant salivary/upper respiratory tract secretions.

The decision on tracheostomy should be taken in advance to ensure timeline planning of the procedure and to avoid performing it in an emergency situation [92]. Importantly, the decision to pursue IV involves an acceptance of further progress of the disease plausibly resulting in a complete loss of motor function. Eye movements are usually spared, but cases of full ophthalmoplegia in patients on long-term mechanical ventilation have been reported [93]. In a Japanese study, 13\% of 709 ALS patients developed a full locked-in state, with the majority of them (70\%) within five years of introducing IV [94].

Thus, to make an informed choice about IV, the patient must be aware of the risk that they might develop locked-in syndrome (LIS) and/or dementia. Unfortunately, a lack of informed consent prior to IV implementation is commonly reported, particularly in emergency situations. Based on data reported in eight studies, emergency introduction occurs in as many as $53 \%$ of cases [95-102].

\section{Prevalence of IV}

Predictors of a favourable attitude towards the use of IV are younger age, male gender, married status, having younger 
children, the concurrent use of PEG, and a higher income $[43,103,100,104-108]$. There was no influence of the site of disease onset $[100,104,109]$. Previous use of NIV is linked to a doubled chance of opting for IV $[100,109,110]$. The most relevant factors in the decision-making process include QoL, severity of disability, ability to return home, possibility of discontinuing mechanical ventilation if one chooses to do so, and concern about the QoL of one's family [111]. Factors proposed to predict successful use of IV are: a highly motivated patient who is sensitive to the needs of his or her family and engaged in the family and/or the community; a slowly progressive course of the disease; a thorough understanding of the alternatives to IV; awareness of the progression of ALS and of the possibility of cognitive impairment; a well-informed family willing to assume the burdens of IV; financial resources for the support network (a healthcare-system-dependent factor); an advance directive for discontinuing IV; and the adaptability of both the patient and their family to constantly change caregivers, equipment, and limitations [112].

Globally, the usage of IV differs greatly due to different healthcare systems and cultural backgrounds [113]. It is rarely proposed in North America for example because the patient's autonomy remains the core basis of management there $[95,113]$. IV is common among Japanese patients where the decision-making is largely left to the physician who is committed to prolonging life [113]. Heterogeneous preferences are observed in Europe [113], with usages of $11.1 \%, 4 \%$, and 1\% in Scotland, Norway, and Ireland, respectively $[54,114,115]$. It is worth noting that a significantly higher rate is observed in patients who are under the care of a respiratory care unit (50\%) [99].

\section{Effect of IV on survival}

Obviously, the support of IV results in longer survival in ALS patients versus individuals who refuse respiratory support. Spataro et al. showed a longer median survival (47 vs 31 months, $\mathrm{p}=0.008)$ in patients who chose IV $(\mathrm{n}=87)$ compared to those who refused tracheostomy $(n=192)$ [104].

The mean survival in patients on IV ranges from eight months to five years $[100,101,104,116]$. In a 10 -year population-based study of 1,260 Italian ALS patients, the overall one-year, three-year, and five-year survival rates on IV were 42.6\% (SE 4.3\%), 22.9\% (SE 3.8\%), and 12.2\% (SE 3.3\%), respectively [100].

Older age (> 60-65), bulbar onset, a lower ALSFRS-r score $(<11)$, no concurrent use of PEG, a lower FVC at baseline, and a single/divorced/widowed status are related to significantly shorter survival in patients using IV [100, 101, 103, 104, 109, 117]. Importantly, concomitant chronic diseases have no influence on the outcome of IV [118]. In a recent study, a steeper BMI decrease prior to the start of IV was related to a significantly faster progression of motor disabilities, including ophthalmoplegia, total quadriplegia, and mouth-opening ability after IV placement [119].
Any deterioration of the clinical state of patients on IV is mainly related to pneumonia, rapidly progressive dyspnoea, nocturnal seizure, or following routine general anaesthesia [118].

The main causes of death in ALS patients using IV are broncho-pneumonia (29\%), hypoxia (25\%), aspiration pneumonia (19\%), pulmonary embolism $(7.5 \%)$, and cardiac ischaemia (1\%) [82].

\section{Effect of IV on QoL}

Contrary to the general perception of IV as a significant burden on the patient, there is complete agreement in the literature that no significant deterioration in QoL occurs due to the use of IV in ALS patients. In particular, Kaub-Wittemer et al. found no significant differences between patients on NIV and IV with regard to the Profile of Mood States (POMS) that assesses feelings and emotional states, and the Munich Quality of Life Dimensions List (MLDL) that evaluates satisfaction with one's physical condition, psyche, social life, and everyday life [97]. Vianello et al. observed a similar prevalence in the use of anti-depressant drugs and the mean Beck Depression Inventory (BDI) and 11-item short-form Life Satisfaction Index (LSI-11) scores in patients with IV compared to those without IV [101]. In agreement with these findings, in a study involving 19 patients in LIS (17 on IV, two on NIV) found that most showed no clinically relevant signs of depression (74\%), or wish for hastened death $(90 \%)$, and stated that they would opt for mechanical ventilation again (90\%) [16]. Rousseau et al. detected comparable scores on the 36-item Short Form Health Survey (SF-36) aimed at assessing overall health status and QoL, in non-LIS and LIS patients with regard to the use of IV [120]. Importantly, no difference was found between patients on NIV and IV with regard to choosing again or recommending their current type of ventilation to other patients ( $94 \%$ vs $81 \%$ and $88 \%$ vs $81 \%$, respectively) [97].

\section{Impact of IV on caregivers}

Despite the possible benefits of IV for ALS patients, such a decision usually brings with it an important financial and care burden for caregivers.

In a study that followed 71 caregivers until the death or tracheostomy of the patient, a higher prevalence of depression at baseline was noted in caregivers of patients who eventually opted for IV than in those whose proxies died (50\% vs 16\%). In both situations, the depression rate declined over time $(8.3 \%$ $v s 10.5 \%$, respectively) after the IV or death of the patient [108]. Among eight caregivers who were interviewed after the patients' tracheostomies, the burden score increased in five, remained stable in two, and declined in one [107]. Although Kaub-Wittemer et al. found comparable results for POMS and MLDL between caregivers of NIV and IV patients [97], there was a strong disagreement with regard to NIV and IV when asked if they would advice their patient to choose ventilation again ( $97 \%$ vs $75 \%, \mathrm{p}=0.008)$ [97]. In this study, $30 \%$ of caregivers rated their own overall QoL as lower than that of 
their respective patient [97]. Similar findings were reported by Linse et al. in a study in which caregivers rated their own QoL and their perceived QoL of their patient as being significantly lower than the actual QoL of the patient [121].

These findings agree with other studies showing that healthy individuals and caregivers perceive the QoL of the patients to be lower, while depression is higher compared to the patients themselves $[16,122]$. This phenomenon has also been found among physicians, whose correct perception of a patient's psychological status depends on their years of experience [123].

A summary of the studies on the use of gastrostomy, NIV and IV is presented in supplementary Tables 3, 4 and 5 , respectively.

\section{Discussion}

The optimal management of patients with ALS requires the protection of autonomy, the improvement or maintenance of QoL, and, importantly, the provision of information in advance of deterioration, especially regarding respiratory failure [118]. Ad hoc decisions lead to poorer outcomes in ALS patients. A discussion with a patient should address all the relevant domains of the therapeutic options, including benefits, risks or constraints, and consequences.

Gastrostomy tube feeding is a useful way of providing nutrition to ALS patients. While the evidence of its effect on survival and QoL is insufficient, improvements in certain domains of life are commonly reported. Due to a strong association between weight loss and a poor outcome in ALS, enteral tube feeding may indirectly have a positive influence on disease outcome by securing the body mass and preventing escalation of muscle wasting.

Overall, there is agreement in the literature about the positive effect that NIV has on patients' survival and QoL. Moreover, NIV remains an effective palliative treatment for symptoms induced by hypoventilation and sleep disturbance. Earlier implementation of NIV seems to result in a greater benefit.

IV is related to longer survival in ALS, but is introduced in emergency situations in up to $50 \%$ of cases, mainly due to a lack of prior informed consent and appropriate discussions. Contrary to expectations, no significant deterioration in QoL has been observed in IV patients, including even those in a locked-in state.

PEG and NIV have not been found to impact upon the burden on caregivers. Conversely, IV has been found to impose a huge burden on caregivers. Indeed, caregivers have expressed a more negative attitude towards IV than patients, although from the time of IV placement there is no further deterioration in QoL for the majority of caregivers.

Comorbid cognitive impairment and neurobehavioural dysfunction affect up to $50 \%$ of patients with ALS, and reduce the efficacy of life-prolonging therapies. These issues mainly affect survival outcome because compliance is rarely achieved under such circumstances [57]. Thus, this group of patients requires more insightful care and monitoring.

In addition, the care of patients with ALS may involve exit strategies such as continuous deep sedation (CDS), physician-assisted suicide (PAS), or euthanasia. Because these strategies are not legal in most countries, only a few studies have investigated these issues. Generally, the wish for hastened death is low even in LIS patients, and declines over the course of the disease, possibly due to the adaptation process [16]. The frequency of PAS or euthanasia is low among patients with ALS, ranging from $5 \%$ in Germany and Switzerland to 20\% in the Netherlands [124-128]. In Dutch patients, the main reasons for life-ceasing therapy are the lack of a chance for improvement, being dependent on others, fear of choking, fatigue and loss of dignity [124].

In conclusion, PEG and NIV are beneficial therapeutic options for ALS patients, while IV may be a reasonable option for some individuals. Timely discussions of these medical interventions should be undertaken to ensure informed and autonomous decision-making regarding their future use.

Conflicts of interest: The authors declare no conflict of interest. Funding: This is an EU Joint Programme - Neurodegenerative Disease Research (JPND; 01ED1405) project. The project is supported through the following organizations under the aegis of JPND - ww.jpnd.eu, e.g. Germany, Bundesministerium für Bildung und Forschung (BMBF, FKZ), Sweden, Vetenskapr å det Sverige, and Poland, Narodowe Centrum Badan I Rozwoju (NCBR).

\section{References}

1. Wijesekera LC, Leigh PN. Amyotrophic lateral sclerosis. Orphanet J Rare Dis. 2009; 4: 3, doi: 10.1186/1750-1172-4-3, indexed in Pubmed: 19192301.

2. Kuźma-Kozakiewicz M. Edaravone in the treatment of amyotrophic lateral sclerosis. Neurol Neurochir Pol. 2018; 52(2): 124-128, doi: 10.1016/j.pjnns.2018.03.004, indexed in Pubmed: 29571701.

3. Lavernhe S, Antoine JC, Court-Fortune I, et al. Home care organization impacts patient management and survival in ALS. Amyotroph Lateral Scler Frontotemporal Degener. 2017; 18(7-8): 562-568, doi: 10.1080/21678421.2017.1332076, indexed in Pubmed: 28585472.

4. Andersen PM, Kuzma-Kozakiewicz M, Keller J, et al. Therapeutic decisions in ALS patients: cross-cultural differences and clinical implications. J Neurol. 2018; 265(7): 1600-1606, doi: 10.1007/s00415018-8861-4, indexed in Pubmed: 29728768.

5. Lulé D, Nonnenmacher S, Sorg S, et al. Live and let die: existential decision processes in a fatal disease. J Neurol. 2014; 261(3): 518-525, doi: 10.1007/s00415-013-7229-z, indexed in Pubmed: 24413639.

6. McGeachan AJ, Hobson EV, Al-Chalabi A, et al. Supportive and symptomatic management of amyotrophic lateral sclerosis. Nat Rev Neurol. 2016; 12(9): 526-538, doi: 10.1038/nrneurol.2016.111, indexed in Pubmed: 27514291.

7. World Health Organization. The World Health Organization Quality of Life Assessment. Field Trial Version for Adults. Administration Manual. Geneva: World Health Organization. ; 1995. 
8. World Health Organization. WHOQoL: measuring quality of life. Geneva: World Health Organization. ; 1997.

9. Goldstein LH, Atkins L, Leigh PN. Correlates of Quality of Life in people with motor neuron disease (MND). Amyotroph Lateral Scler Other Motor Neuron Disord. 2002; 3(3): 123-129, doi: 10.1080/146608202760834120, indexed in Pubmed: 12495573.

10. Simmons Z, Bremer BA, Robbins RA, et al. Quality of life in ALS depends on factors other than strength and physical function. Neurology. 2000; 55(3): 388-392, doi: 10.1212/wnl.55.3.388, indexed in Pubmed: 10932273.

11. Robbins RA, Simmons Z, Bremer BA, et al. Quality of life in ALS is maintained as physical function declines. Neurology. 2001; 56(4): 442444, doi: 10.1212/wnl.56.4.442, indexed in Pubmed: 11222784.

12. Neudert C, Wasner M, Borasio GD. Patients' assessment of quality of life instruments: a randomised study of SIP, SF-36 and SEIQoL-DW in patients with amyotrophic lateral sclerosis. J Neurol Sci. 2001; 191(1-2): 103-109, doi: 10.1016/s0022-510x(01)00612-8, indexed in Pubmed: 11676999.

13. Ganzini L, Johnston WS, Hoffman WF. Correlates of suffering in amyotrophic lateral sclerosis. Neurology. 1999; 52(7): 1434-1440, doi: 10.1212/wnl.52.7.1434, indexed in Pubmed: 10227631.

14. Clarke S, Hickey A, O'Boyle C, et al. Assessing individual quality of life in amyotrophic lateral sclerosis. Qual Life Res. 2001; 10(2): 149-158, doi: 10.1023/a:1016704906100, indexed in Pubmed: 11642685.

15. Lulé D, Zickler C, Häcker S, et al. Life can be worth living in locked-in syndrome. Prog Brain Res. 2009; 177: 339-351, doi: 10.1016/ S0079-6123(09)17723-3, indexed in Pubmed: 19818912.

16. Kuzma-Kozakiewicz M, Andersen PM, Ciecwierska K, et al. An observational study on quality of life and preferences to sustain life in locked-in state. Neurology. 2019; 93(10): e938-e945, doi: 10.1212/ WNL.0000000000008064, indexed in Pubmed: 31391247.

17. Körner S, Hendricks M, Kollewe $\mathrm{K}$, et al. Weight loss, dysphagia and supplement intake in patients with amyotrophic lateral sclerosis (ALS): impact on quality of life and therapeutic options. BMC Neurol. 2013; 13: 84, doi: 10.1186/1471-2377-13-84, indexed in Pubmed: 23848967.

18. Desport JC, Preux PM, Truong CT, et al. Nutritional status is a prognostic factor for survival in ALS patients. Neurology. 1999; 53(5): 1059 1063, doi: 10.1212/wnl.53.5.1059, indexed in Pubmed: 10496266.

19. Desport JC, Preux PM, Truong CT, et al. Nutritional status is a prognostic factor for survival in ALS patients. Neurology. 1999; 53(5): 1059 1063, doi: 10.1212/wnl.53.5.1059, indexed in Pubmed: 10496266.

20. Bouteloup C, Desport JC, Clavelou P, et al. Hypermetabolism in ALS patients: an early and persistent phenomenon. J Neurol. 2009; 256(8): 1236-1242, doi: 10.1007/s00415-009-5100-z, indexed in Pubmed: 19306035.

21. Vaisman N, Lusaus M, Nefussy B, et al. Do patients with amyotrophic lateral sclerosis (ALS) have increased energy needs? J Neurol Sci. 2009; 279(1-2): 26-29, doi: 10.1016/j.jns.2008.12.027, indexed in Pubmed: 19185883.

22. Desport JC, Torny F, Lacoste M, et al. Hypermetabolism in ALS: correlations with clinical and paraclinical parameters. Neurodegener Dis. 2005; 2(3-4): 202-207, doi: 10.1159/000089626, indexed in Pubmed: 16909026.

23. Jeejeebhoy KN. Muscle function and nutrition. Gut. 1986; 27 Suppl 1: 25-39, doi: 10.1136/gut.27.suppl_1.25, indexed in Pubmed: 3539710.

24. Lopes J, Russell DM, Whitwell J, et al. Skeletal muscle function in malnutrition. Am J Clin Nutr. 1982; 36(4): 602-610, doi: 10.1093/ ajcn/36.4.602, indexed in Pubmed: 6812409.
25. Andersen PM, Abrahams S, Borasio GD, et al. EFNS Task Force on Diagnosis and Management of Amyotrophic Lateral Sclerosis:. EFNS guidelines on the clinical management of amyotrophic lateral sclerosis (MALS)--revised report of an EFNS task force. Eur J Neurol. 2012; 19(3): 360-375, doi: 10.1111/j.1468-1331.2011.03501.x, indexed in Pubmed: 21914052.

26. Scott AG, Austin HE. Nasogastric feeding in the management of severe dysphagia in motor neurone disease. Palliat Med. 1994; 8(1): 45-49, doi: 10.1177/026921639400800108, indexed in Pubmed: 8180740.

27. Gastrostomy in patients with amyotrophic lateral sclerosis (ProGas): a prospective cohort study. The Lancet Neurology. 2015; 14(7): 702709, doi: 10.1016/s1474-4422(15)00104-0.

28. Mazzini L, Corrà T, Zaccala M, et al. Percutaneous endoscopic gastrostomy and enteral nutrition in amyotrophic lateral sclerosis. J Neurol. 1995; 242(10): 695-698, doi: 10.1007/BF00866922, indexed in Pubmed: 8568533.

29. Bokuda K, Shimizu T, Imamura K, et al. Predictive factors for prognosis following unsedated percutaneous endoscopic gastrostomy in ALS patients. Muscle Nerve. 2016; 54(2): 277-283, doi: 10.1002/ mus.25051, indexed in Pubmed: 26799526.

30. Kasarskis EJ, Scarlata D, Hill R, et al. A retrospective study of percutaneous endoscopic gastrostomy in ALS patients during the BDNF and CNTF trials. J Neurol Sci. 1999; 169(1-2): 118-125, doi: 10.1016/ s0022-510x(99)00230-0, indexed in Pubmed: 10540019.

31. Allen JA, Chen R, Ajroud-Driss S, et al. Gastrostomy tube placement by endoscopy versus radiologic methods in patients with ALS: a retrospective study of complications and outcome. Amyotroph Lateral Scler Frontotemporal Degener. 2013; 14(4): 308-314, doi: 10.3109/21678421.2012.751613, indexed in Pubmed: 23286755.

32. Blondet A, Lebigot J, Nicolas G, et al. Radiologic versus endoscopic placement of percutaneous gastrostomy in amyotrophic lateral sclerosis: multivariate analysis of tolerance, efficacy, and survival. J Vasc Interv Radiol. 2010; 21(4): 527-533, doi: 10.1016/j.jvir.2009.11.022, indexed in Pubmed: 20172742.

33. Thornton FJ, Fotheringham T, Haslam PJ, et al. Amyotrophic lateral sclerosis: enteral nutrition provision-endoscopic or radiologic gastrostomy? Radiology. 2002; 224(3): 713-717, doi: 10.1148/radiol.2243010909, indexed in Pubmed: 12202704.

34. Chiò A, Galletti R, Finocchiaro C, et al. Percutaneous radiological gastrostomy: a safe and effective method of nutritional tube placement in advanced ALS. J Neurol Neurosurg Psychiatry. 2004; 75(4): 645-647, doi: 10.1136/jnnp.2003.020347, indexed in Pubmed: 15026518.

35. Shaw AS, Ampong MA, Rio A, et al. Survival of patients with ALS following institution of enteral feeding is related to pre-procedure oximetry: a retrospective review of 98 patients in a single centre. Amyotroph Lateral Scler. 2006; 7(1): 16-21, doi: 10.1080/14660820510012013, indexed in Pubmed: 16546754.

36. Yang B, Shi X. Percutaneous endoscopic gastrostomy versus fluoroscopic gastrostomy in amyotrophic lateral sclerosis (ALS) sufferers with nutritional impairment: A meta-analysis of current studies. Oncotarget. 2017; 8(60): 102244-102253, doi: 10.18632/oncotarget.22288, indexed in Pubmed: 29254240.

37. Sancho J, Servera E, Chiner E, et al. Noninvasive respiratory muscle aids during PEG placement in ALS patients with severe ventilatory impairment. J Neurol Sci. 2010; 297(1-2): 55-59, doi: 10.1016/j. jns.2010.06.022, indexed in Pubmed: 20659743.

38. Czell D, Bauer M, Binek J, et al. Outcomes of percutaneous endoscopic gastrostomy tube insertion in respiratory impaired amyotrophic lateral sclerosis patients under noninvasive ventilation. Respir Care. 
2013; 58(5): 838-844, doi: $10.4187 /$ respcare.02024, indexed in Pubmed: 23107129.

39. Desport JC, Mabrouk T, Bouillet $P$, et al. Complications and survival following radiologically and endoscopically-guided gastrostomy in patients with amyotrophic lateral sclerosis. Amyotroph Lateral Scler Other Motor Neuron Disord. 2005; 6(2): 88-93, doi: 10.1080/14660820410021258, indexed in Pubmed: 16036431.

40. Barć K, Weber C, Maksymowicz-Śliwińska A, et al. Healthcare provision in amyotrophic lateral sclerosis: procedures, queries and pitfalls in Germany and Poland. Amyotroph Lateral Scler Frontotemporal Degener. 2020; 21(3-4): 193-202, doi: 10.1080/21678421.2020.1746345, indexed in Pubmed: 32290712.

41. Albert SM, Murphy PL, Del Bene M, et al. Incidence and predictors of PEG placement in ALS/MND. J Neurol Sci. 2001; 191(1-2): 115119, doi: 10.1016/s0022-510x(01)00614-1, indexed in Pubmed: 11677001.

42. Zhang L, Sanders L, Fraser RJL. Nutritional support teams increase percutaneous endoscopic gastrostomy uptake in motor neuron disease. World J Gastroenterol. 2012; 18(44): 6461-7; discussion p.6466, doi: 10.3748/wjg.v18.i44.6461, indexed in Pubmed: 23197892.

43. Mitsumoto H, Davidson M, Moore D, et al. ALS CARE Study Group. Percutaneous endoscopic gastrostomy (PEG) in patients with ALS and bulbar dysfunction. Amyotroph Lateral Scler Other Motor Neuron Disord. 2003; 4(3): 177-185, doi: 10.1080/14660820310011728, indexed in Pubmed: 13129795.

44. Dupuis L, Pradat PF, Ludolph A, et al. Energy metabolism in amyotrophic lateral sclerosis. The Lancet Neurology. 2011; 10(1): 75-82, doi: 10.1016/s1474-4422(10)70224-6.

45. Rosenfeld J, Ellis A. Nutrition and dietary supplements in motor neuron disease. Phys Med Rehabil Clin N Am. 2008; 19(3): 573-89, x, doi: 10.1016/j.pmr.2008.03.001, indexed in Pubmed: 18625417.

46. Paganoni S, Deng J, Jaffa M, et al. Body mass index, not dyslipidemia, is an independent predictor of survival in amyotrophic lateral sclerosis. Muscle Nerve. 2011; 44(1): 20-24, doi: 10.1002/mus.22114, indexed in Pubmed: 21607987.

47. Chiò A, Finocchiaro E, Meineri $P$, et al. Safety and factors related to survival after percutaneous endoscopic gastrostomy in ALS. ALS Percutaneous Endoscopic Gastrostomy Study Group. Neurology. 1999; 53(5): 1123-1125, doi: 10.1212/wnl.53.5.1123, indexed in Pubmed: 10496278.

48. Dorst J, Dupuis L, Petri S, et al. Percutaneous endoscopic gastrostomy in amyotrophic lateral sclerosis: a prospective observational study. J Neurol. 2015; 262(4): 849-858, doi: 10.1007/s00415-015-7646-2, indexed in Pubmed: 25618254.

49. Del Pi, Occhipinti P, Orsello M, et al. Percutaneous endoscopic gastrostomy (PEG) reduces complications and improves survival in amyotrophic lateral sclerosis (ALS). Gastrointest Endosc. 1999; 49: AB192.

50. Reich-Slotky R, Andrews J, Cheng B, et al. Body mass index (BMI) as predictor of ALSFRS-R score decline in ALS patients. Amyotroph Lateral Scler Frontotemporal Degener. 2013; 14(3): 212-216, doi: 10.3109/21678421.2013.770028, indexed in Pubmed: 23452274.

51. Ngo ST, Steyn FJ, McCombe PA. Body mass index and dietary intervention: implications for prognosis of amyotrophic lateral sclerosis. J Neurol Sci. 2014; 340(1-2): 5-12, doi: 10.1016/j.jns.2014.02.035, indexed in Pubmed: 24629478.

52. Mathus-Vliegen LM, Louwerse LS, Merkus MP, et al. Percutaneous endoscopic gastrostomy in patients with amyotrophic lateral sclerosis and impaired pulmonary function. Gastrointest Endosc. 1994;
40(4): 463-469, doi: 10.1016/s0016-5107(94)70211-x, indexed in Pubmed: 7926537.

53. Salachas F, Fourmestraux AR, Le Fo, et al. Gastrostomy in patients with amyotrophic lateral sclerosis: a retrospective study in 110 patients. in: 7th International Symposium on ALS/MND, Chicago. : IL1996.

54. Forbes RB, Colville S, Swingler RJ, et al. Scottish Motor Neurone Disease Research Group. Frequency, timing and outcome of gastrostomy tubes for amyotrophic lateral sclerosis/motor neurone disease-a record linkage study from the Scottish Motor Neurone Disease Register. J Neurol. 2004; 251(7): 813-817, doi: 10.1007/s00415-0040429-9, indexed in Pubmed: 15258782.

55. Miller RG, Jackson CE, Kasarskis EJ, et al. Quality Standards Subcommittee of the American Academy of Neurology. Practice parameter update: the care of the patient with amyotrophic lateral sclerosis: drug, nutritional, and respiratory therapies (an evidence-based review): report of the Quality Standards Subcommittee of the American Academy of Neurology. Neurology. 2009; 73(15): 1218-1226, doi: 10.1212/WNL.0b013e3181bc0141, indexed in Pubmed: 19822872.

56. Finocchiaro E, Point MCDa, Chid A, et al. P.28 Percutaneous endoscopic gastrostomy inpatients with amyotrophic lateral sclerosis. Clinical Nutrition. 1998; 17: 37, doi: 10.1016/s0261-5614(98)80184-2.

57. Chiò A, llardi A, Cammarosano S, et al. Neurobehavioral dysfunction in ALS has a negative effect on outcome and use of PEG and NIV. Neurology. 2012; 78(14): 1085-1089, doi: 10.1212/ WNL.0b013e31824e8f53, indexed in Pubmed: 22442427.

58. Strong MJ, Rowe A, Rankin RN. Percutaneous gastrojejunostomy in amyotrophic lateral sclerosis. J Neurol Sci. 1999; 169(1-2): 128132, doi: 10.1016/s0022-510x(99)00235-x, indexed in Pubmed: 10540021.

59. Mitchell SL, Tetroe JM. Survival after percutaneous endoscopic gastrostomy placement in older persons. J Gerontol A Biol Sci Med Sci. 2000; 55(12): M735-M739, doi: 10.1093/gerona/55.12.m735, indexed in Pubmed: 11129395.

60. Spataro R, Ficano L, Piccoli F, et al. Percutaneous endoscopic gastrostomy in amyotrophic lateral sclerosis: effect on survival. J Neurol Sci. 2011; 304(1-2): 44-48, doi: 10.1016/j.jns.2011.02.016, indexed in Pubmed: 21371720.

61. Cui F, Sun L, Xiong J, et al. Therapeutic effects of percutaneous endoscopic gastrostomy on survival in patients with amyotrophic lateral sclerosis: A meta-analysis. PLoS One. 2018; 13(2): e0192243, doi 10.1371/journal.pone.0192243, indexed in Pubmed: 29408898.

62. Zamietra K, Lehman EB, Felgoise SH, et al. Non-invasive ventilation and gastrostomy may not impact overall quality of life in patients with ALS. Amyotroph Lateral Scler. 2012; 13(1): 55-58, doi: 10.3109/17482968.2011.641570, indexed in Pubmed: 22214353.

63. Trail M, Nelson ND, Van JN, et al. A study comparing patients with amyotrophic lateral sclerosis and their caregivers on measures of quality of life, depression, and their attitudes toward treatment options. J Neurol Sci. 2003; 209(1-2): 79-85, doi: 10.1016/s0022-510x(03)00003-0, indexed in Pubmed: 12686407.

64. Lo Coco D, Marchese S, Corrao S, et al. Development of chronic hypoventilation in amyotrophic lateral sclerosis patients. Respir Med. 2006; 100(6): 1028-1036, doi: 10.1016/j.rmed.2005.09.035, indexed in Pubmed: 16278079.

65. Kaplan LM, Hollander D. Respiratory dysfunction in amyotrophic lateral sclerosis. Clin Chest Med. 1994; 15(4): 675-681, indexed in Pubmed: 7867282.

66. Miller RG, Rosenberg JA, Gelinas DF, et al. Practice parameter: the care of the patient with amyotrophic lateral sclerosis (an evidence- 
-based review): report of the Quality Standards Subcommittee of the American Academy of Neurology: ALS Practice Parameters Task Force. Neurology. 1999; 52(7): 1311-1323, doi: 10.1212/wnl.52.7.1311, indexed in Pubmed: 10227612.

67. Stambler N, Charatan M, Cedarbaum JM. Prognostic indicators of survival in ALS. ALS CNTF Treatment Study Group. Neurology. 1998; 50(1): 66-72, doi: 10.1212/wnl.50.1.66, indexed in Pubmed: 9443459.

68. Kleopa KA, Sherman M, Neal B, et al. Bipap improves survival and rate of pulmonary function decline in patients with ALS. J Neurol Sci. 1999; 164(1): 82-88, doi: 10.1016/s0022-510x(99)00045-3, indexed in Pubmed: 10385053.

69. Morgan RK, McNally S, Alexander M, et al. Use of Sniff nasal-inspiratory force to predict survival in amyotrophic lateral sclerosis. Am J Respir Crit Care Med. 2005; 171(3): 269-274, doi: 10.1164/rccm.200403-3140C, indexed in Pubmed: 15516537.

70. Clinical indications for noninvasive positive pressure ventilation in chronic respiratory failure due to restrictive lung disease, COPD, and nocturnal hypoventilation--a consensus conference report. Chest. 1999; 116(2): 521-534, doi: 10.1378/chest.116.2.521, indexed in Pubmed: 10453883.

71. Jackson CE, Rosenfeld J, Moore DH, et al. A preliminary evaluation of a prospective study of pulmonary function studies and symptoms of hypoventilation in ALS/MND patients. J Neurol Sci. 2001; 191(1-2): 75-78, doi: 10.1016/s0022-510x(01)00617-7, indexed in Pubmed: 11676995.

72. Allen SM, Hunt B, Green M. Fall in vital capacity with posture. Br J Dis Chest. 1985; 79(3): 267-271, indexed in Pubmed: 4015957.

73. Fallat RJ, Jewitt B, Bass M, et al. Spirometry in amyotrophic lateral sclerosis. Arch Neurol. 1979; 36(2): 74-80, doi: 10.1001/archneur.1979.00500380044004, indexed in Pubmed: 420626.

74. Nickol AH, Hart N, Hopkinson NS, et al. Mechanisms of improvement of respiratory failure in patients with restrictive thoracic disease treated with non-invasive ventilation. Thorax. 2005; 60(9): 754-760, doi: 10.1136/thx.2004.039388, indexed in Pubmed: 15939731.

75. Gonzalez-Bermejo J, Morelot-Panzini C, Arnol N, et al. Prognostic value of efficiently correcting nocturnal desaturations after one month of non-invasive ventilation in amyotrophic lateral sclerosis: a retrospective monocentre observational cohort study. Amyotroph Lateral Scler Frontotemporal Degener. 2013; 14(5-6): 373-379, doi: 10.3109/21678421.2013.776086, indexed in Pubmed: 23527531.

76. Aboussouan LS, Khan SU, Banerjee M, et al. Objective measures of the efficacy of noninvasive positive-pressure ventilation in amyotrophic lateral sclerosis. Muscle Nerve. 2001; 24(3): 403-409, doi: 10.1002/1097-4598(200103)24:3<403::aid-mus1013>3.0.co;2-3, indexed in Pubmed: 11353427.

77. Gruis KL, Brown DL, Schoennemann A, et al. Predictors of noninvasive ventilation tolerance in patients with amyotrophic lateral sclerosis. Muscle Nerve. 2005; 32(6): 808-811, doi: 10.1002/mus.20415, indexed in Pubmed: 16094653.

78. Sheers N, Berlowitz DJ, Rautela L, et al. Improved survival with an ambulatory model of non-invasive ventilation implementation in motor neuron disease. Amyotroph Lateral Scler Frontotemporal Degener. 2014; 15(3-4): 180-184, doi: 10.3109/21678421.2014.881376, indexed in Pubmed: 24555916.

79. Bertella E, Banfi P, Paneroni M, et al. Early initiation of night-time NIV in an outpatient setting: a randomized non-inferiority study in ALS patients. Eur J Phys Rehabil Med. 2017; 53(6): 892-899, doi: 10.23736/S1973-9087.17.04511-7, indexed in Pubmed: 28382811.

80. Bourke SC, Tomlinson M, Williams TL, et al. Effects of non-invasive ventilation on survival and quality of life in patients with amyotrophic lateral sclerosis: a randomised controlled trial. Lancet Neurol. 2006; 5(2): 140-147, doi: 10.1016/S1474-4422(05)70326-4, indexed in Pubmed: 16426990.

81. Pinto AC, Evangelista T, Carvalho M, et al. Respiratory assistance with a non-invasive ventilator (Bipap) in MND/ALS patients: Survival rates in a controlled trial. Journal of the Neurological Sciences. 1995; 129: 19-26, doi: 10.1016/0022-510x(95)00052-4.

82. Burkhardt C, Neuwirth C, Sommacal A, et al. Is survival improved by the use of NIV and PEG in amyotrophic lateral sclerosis (ALS)? A post-mortem study of 80 ALS patients. PLoS One. 2017; 12(5): e0177555, doi: 10.1371/journal.pone.0177555, indexed in Pubmed: 28542233.

83. Lechtzin N, Scott Y, Busse AM, et al. Early use of non-invasive ventilation prolongs survival in subjects with ALS. Amyotroph Lateral Scler. 2007; 8(3): 185-188, doi: 10.1080/17482960701262392, indexed in Pubmed: 17538782.

84. Pinto A, de Carvalho M, Evangelista T, et al. Nocturnal pulse oximetry: a new approach to establish the appropriate time for non-invasive ventilation in ALS patients. Amyotroph Lateral Scler Other Motor Neuron Disord. 2003; 4(1): 31-35, doi: 10.1080/14660820310006706, indexed in Pubmed: 12745616.

85. Mustfa N, Walsh E, Bryant V, et al. The effect of noninvasive ventilation on ALS patients and their caregivers. Neurology. 2006; 66(8): 1211-1217, doi: 10.1212/01.wnl.0000208957.88534.11, indexed in Pubmed: 16636239.

86. Bourke SC, Shaw PJ, Gibson GJ. Respiratory function vs sleep-disordered breathing as predictors of QOL in ALS. Neurology. 2001; 57(11): 20402044, doi: 10.1212/wnl.57.11.2040, indexed in Pubmed: 11739823.

87. Newsom-Davis IC, Lyall RA, Leigh PN, et al. The effect of non-invasive positive pressure ventilation (NIPPV) on cognitive function in amyotrophic lateral sclerosis (ALS): a prospective study. J Neurol Neurosurg Psychiatry. 2001; 71(4): 482-487, doi: 10.1136/jnnp.71.4.482, indexed in Pubmed: 11561031.

88. Bourke SC, Bullock RE, Williams TL, et al. Noninvasive ventilation in ALS: indications and effect on quality of life. Neurology. 2003; 61(2): 171-177, doi: 10.1212/01.wnl.0000076182.13137.38, indexed in Pubmed: 12874394.

89. Lo Coco D, Marchese S, Pesco MC, et al. Noninvasive positive-pressure ventilation in ALS: predictors of tolerance and survival. Neurology. 2006; 67(5): 761-765, doi: 10.1212/01.wnl.0000227785.73714.64, indexed in Pubmed: 16899545.

90. Mahajan KR, Bach JR, Saporito L, et al. Diaphragm pacing and noninvasive respiratory management of amyotrophic lateral sclerosis/ motor neuron disease. Muscle Nerve. 2012; 46(6): 851-855, doi: 10.1002/mus.23663, indexed in Pubmed: 23042087.

91. Schiffman P, Belsh J. Pulmonary Function at Diagnosis of Amyotrophic Lateral Sclerosis. Chest. 1993; 103(2): 508-513, doi: 10.1378/ chest.103.2.508.

92. Radunovic A, Annane D, Rafiq MK, et al. Mechanical ventilation for amyotrophic lateral sclerosis/motor neuron disease. Cochrane Database Syst Rev. 2017; 10: CD004427, doi: 10.1002/14651858. CD004427.pub4, indexed in Pubmed: 28982219.

93. Mizutani T, Aki M, Shiozawa R, et al. Development of ophthalmoplegia in amyotrophic lateral sclerosis during long-term use of respirators. J Neurol Sci. 1990; 99(2-3): 311-319, doi: 10.1016/0022-510x(90)90165-j, indexed in Pubmed: 2086731.

94. Kawata A, Mizoguchi K, Hayashi H. [A nationwide survey of ALS patients on trachoestomy positive pressure ventilation (TPPV) who developed a totally locked-in state (TLS) in Japan]. Rinsho Shinkeigaku. 2008; 48(7): 476480, doi: 10.5692/clinicalneurol.48.476, indexed in Pubmed: 18717180. 
95. Moss AH, Oppenheimer EA, Casey P, et al. Patients with amyotrophic lateral sclerosis receiving long-term mechanical ventilation. Advance care planning and outcomes. Chest. 1996; 110(1): 249-255, doi: 10.1378/chest.110.1.249, indexed in Pubmed: 8681635.

96. Cazzolli PA, Oppenheimer EA. Home mechanical ventilation for amyotrophic lateral sclerosis: nasal compared to tracheostomy-intermittent positive pressure ventilation. J Neurol Sci. 1996; 139 Suppl: 123128, doi: 10.1016/0022-510x(96)00099-8, indexed in Pubmed: 8899671.

97. Kaub-Wittemer D, Steinbüchel Nv, Wasner M, et al. Quality of life and psychosocial issues in ventilated patients with amyotrophic lateral sclerosis and their caregivers. J Pain Symptom Manage. 2003; 26(4): 890-896, doi: 10.1016/s0885-3924(03)00323-3, indexed in Pubmed: 14527757.

98. Hirano YM, Yamazaki Y, Shimizu J, et al. Ventilator dependence and expressions of need: a study of patients with amyotrophic lateral sclerosis in Japan. Soc Sci Med. 2006; 62(6): 1403-1413, doi: 10.1016/j.socscimed.2005.08.015, indexed in Pubmed: 16263201.

99. Sancho J, Servera E, Bañuls P, et al. Prolonging survival in amyotrophic lateral sclerosis: efficacy of noninvasive ventilation and uncuffed tracheostomy tubes. Am J Phys Med Rehabil. 2010; 89(5): 407-411, doi: 10.1097/PHM.0b013e3181d8a479, indexed in Pubmed: 20407306.

100. Chiò A, Calvo A, Ghiglione P, et al. PARALS. Tracheostomy in amyotrophic lateral sclerosis: a 10-year population-based study in Italy. J Neurol Neurosurg Psychiatry. 2010; 81(10): 1141-1143, doi: 10.1136/jnnp.2009.175984, indexed in Pubmed: 20660920.

101. Vianello A, Arcaro G, Palmieri A, et al. Survival and quality of life after tracheostomy for acute respiratory failure in patients with amyotrophic lateral sclerosis. J Crit Care. 2011; 26(3): 329.e7-329.14, doi: 10.1016/j.jcrc.2010.06.003, indexed in Pubmed: 20655697.

102. Sancho J, Servera E, Díaz JL, et al. Home tracheotomy mechanical ventilation in patients with amyotrophic lateral sclerosis: causes, complications and 1-year survival. Thorax. 2011; 66(11): 948-952, doi: 10.1136/thx.2011.160481, indexed in Pubmed: 21693569.

103. Lo Coco D, Marchese S, La Bella V, et al. The amyotrophic lateral sclerosis functional rating scale predicts survival time in amyotrophic lateral sclerosis patients on invasive mechanical ventilation. Chest. 2007; 132(1): 64-69, doi: 10.1378/chest.06-2712, indexed in Pubmed: 17475635.

104. Spataro R, Bono V, Marchese S, et al. Tracheostomy mechanical ventilation in patients with amyotrophic lateral sclerosis: clinical features and survival analysis. J Neurol Sci. 2012; 323(1-2): 66-70, doi: 10.1016/j.jns.2012.08.011, indexed in Pubmed: 22989611.

105. Laub M, Midgren B. Survival of patients on home mechanical ventilation: a nationwide prospective study. Respir Med. 2007; 101(6): 1074-1078, doi: 10.1016/j.rmed.2006.10.007, indexed in Pubmed: 17118638.

106. Rabkin JG, Albert SM, Tider T, et al. Predictors and course of elective long-term mechanical ventilation: A prospective study of ALS patients. Amyotroph Lateral Scler. 2006; 7(2): 86-95, doi: 10.1080/14660820500515021, indexed in Pubmed: 16753972.

107. Albert SM, Whitaker A, Rabkin JG, et al. Medical and supportive care among people with ALS in the months before death or tracheostomy. J Pain Symptom Manage. 2009; 38(4): 546-553, doi: 10.1016/j. jpainsymman.2008.11.013, indexed in Pubmed: 19540088.

108. Rabkin JG, Albert SM, Rowland LP, et al. How common is depression among ALS caregivers? A longitudinal study. Amyotroph Lateral Scler. 2009; 10(5-6): 448-455, doi: 10.3109/17482960802459889, indexed in Pubmed: 19922139.
109. Tagami M, Kimura F, Nakajima H, et al. Tracheostomy and invasive ventilation in Japanese ALS patients: decision-making and survival analysis: 1990-2010. J Neurol Sci. 2014; 344(1-2): 158-164, doi: 10.1016/j.jns.2014.06.047, indexed in Pubmed: 25017882.

110. Chiò A, Calvo A, Moglia C, et al. PARALS. Non-invasive ventilation in amyotrophic lateral sclerosis: a 10 year population based study. J Neurol Neurosurg Psychiatry. 2012; 83(4): 377-381, doi: 10.1136/ jnnp-2011-300472, indexed in Pubmed: 22013242.

111. Young JM, Marshall CL, Anderson EJ. Amyotrophic lateral sclerosis patients' perspectives on use of mechanical ventilation. Health Soc Work. 1994; 19(4): 253-260, doi: 10.1093/hsw/19.4.253, indexed in Pubmed: 7813963.

112. Lyall R, Gelinas D. Control of symtoms: dysnoea and resiratory symtoms. In: Oliver DB, GD; Walsh, D, editor. Palliative care in amyotrohic lateral sclerosis From diagnosis to bereavement. Oxford: Oxford University Press; 2006. p. : 63-93.

113. Borasio GD, Gelinas DF, Yanagisawa N. Mechanical ventilation in amyotrophic lateral sclerosis: a cross-cultural perspective. J Neurol. 1998; 245 Suppl 2: S7-12; discussion S29, doi: 10.1007/ s004150050641, indexed in Pubmed: 9747928.

114. Benjaminsen E, Alstadhaug KB, Gulsvik M, et al. Amyotrop hic lateral sclerosis in Nordland county, Norway, 2000-2015: prevalence, incidence, and clinical features. Amyotroph Lateral Scler Frontotemporal Degener. 2018; 19(7-8): 522-527, doi: 10.1080/21678421.2018.1513534, indexed in Pubmed: 30265157.

115. O'Toole 0, Traynor BJ, Brennan P, et al. Epidemiology and clinical features of amyotrophic lateral sclerosis in Ireland between 1995 and 2004. J Neurol Neurosurg Psychiatry. 2008; 79(1): 30-32, doi: 10.1136/jnnp.2007.117788, indexed in Pubmed: 17634215.

116. Atsuta $\mathrm{N}$, Watanabe $\mathrm{H}$, Ito $\mathrm{M}$, et al. Research Committee on the Neurodegenerative Diseases of Japan. Age at onset influences on wide-ranged clinical features of sporadic amyotrophic lateral sclerosis. J Neurol Sci. 2009; 276(1-2): 163-169, doi: 10.1016/j. jns.2008.09.024, indexed in Pubmed: 18962725.

117. Stoller JK, Xu M, Mascha E, et al. Long-term outcomes for patients discharged from a long-term hospital-based weaning unit. Chest 2003; 124(5): 1892-1899, doi: 10.1378/chest.124.5.1892, indexed in Pubmed: 14605065.

118. Bradley MD, Orrell RW, Clarke J, et al. Outcome of ventilatory support for acute respiratory failure in motor neurone disease. J Neurol Neurosurg Psychiatry. 2002; 72(6): 752-756, doi: 10.1136/ jnnp.72.6.752, indexed in Pubmed: 12023419.

119. Nakayama Y, Shimizu T, Matsuda C, et al. Body weight variation predicts disease progression after invasive ventilation in amyotrophic lateral sclerosis. Sci Rep. 2019; 9(1): 12262, doi: 10.1038/s41598 019-48831-9, indexed in Pubmed: 31439899.

120. Rousseau MC, Pietra S, Blaya J, et al. Quality of life of ALS and LIS patients with and without invasive mechanical ventilation. J Neurol. 2011; 258(10): 1801-1804, doi: 10.1007/s00415-011-6018-9, indexed in Pubmed: 21461685.

121. Linse K, Rüger W, Joos M, et al. Eye-tracking-based assessment suggests preserved well-being in locked-in patients. Ann Neurol. 2017; 81(2): 310-315, doi: 10.1002/ana.24871, indexed in Pubmed: 28074605.

122. Lulé D, Ehlich B, Lang D, et al. Quality of life in fatal disease: the flawed judgement of the social environment. J Neurol. 2013; 260(11): 2836-2843, doi: 10.1007/s00415-013-7068-y, indexed in Pubmed: 23989341. 
123. Aho-Özhan HEA, Böhm S, Keller J, et al. Experience matters: neurologists' perspectives on ALS patients' well-being. J Neurol. 2017; 264(4): 639-646, doi: 10.1007/s00415-016-8382-y, indexed in Pubmed: 28120043.

124. Maessen M, Veldink JH, Onwuteaka-Philipsen BD, et al. Trends and determinants of end-of-life practices in ALS in the Netherlands. Neurology. 2009; 73(12): 954-961, doi: 10.1212/ WNL.0b013e3181b87983, indexed in Pubmed: 19770471.

125. Hecht M, Hillemacher T, Gräsel E, et al. Subjective experience and coping in ALS. Amyotroph Lateral Scler Other Motor Neuron Disord. 2002; 3(4): 225-231, doi: 10.1080/146608202760839009, indexed in Pubmed: 12710513.

126. Kühnlein $\mathrm{P}$, Kübler $\mathrm{A}$, Raubold $\mathrm{S}$, et al. Palliative care and circumstances of dying in German ALS patients using non-invasive ventilation. Amyotroph Lateral Scler. 2008; 9(2): 91-98, doi: 10.1080/17482960701830495, indexed in Pubmed: 18428001.

127. Stutzki R, Schneider U, Reiter-Theil S, et al. Attitudes Toward Assisted Suicide and Life-Prolonging Measures in Swiss ALS Patients and Their Caregivers. Front Psychol. 2012; 3: 443, doi: 10.3389/ fpsyg.2012.00443, indexed in Pubmed: 23112784.

128. Maessen M, Veldink JH, Onwuteaka-Philipsen BD, et al. Euthanasia and physician-assisted suicide among patients with amyotrophic lateral sclerosis in the Netherlands. N Engl J Med. 2002; 346(21): 1638-1644, doi: 10.1056/NEJMsa012739, indexed in Pubmed: 12023997.

129. Leigh PN, Abrahams S, Al-Chalabi A, et al. King's MND Care and Research Team. The management of motor neurone disease. J Neurol Neurosurg Psychiatry. 2003; 74 Suppl 4: iv32-iv47, doi: 10.1136/ jnnp.74.suppl_4.iv32, indexed in Pubmed: 14645465.

130. Aboussouan LS, Khan SU, Meeker DP, et al. Effect of noninvasive positive-pressure ventilation on survival in amyotrophic lateral scle- rosis. Ann Intern Med. 1997; 127(6): 450-453, doi: 10.7326/00034819-127-6-199709150-00006, indexed in Pubmed: 9313002.

131. Elman LB, Siderowf AD, McCluskey LF. Nocturnal oximetry: utility in the respiratory management of amyotrophic lateral sclerosis. Am J Phys Med Rehabil. 2003; 82(11): 866-870, doi: 10.1097/01. PHM.0000091985.22659.30, indexed in Pubmed: 14566155.

132. Sivak ED, Shefner JM, Mitsumoto $H$, et al. The use of non-invasive positive pressure ventilation (NIPPV) in ALS patients. A need for improved determination of intervention timing. Amyotroph Lateral Scler Other Motor Neuron Disord. 2001; 2(3): 139-145, doi: 10.1080/146608201753275724, indexed in Pubmed: 11771770.

133. Morgan RK, McNally S, Alexander M, et al. Use of Sniff nasal-inspiratory force to predict survival in amyotrophic lateral sclerosis. Am J Respir Crit Care Med. 2005; 171(3): 269-274, doi: 10.1164/ rccm.200403-3140C, indexed in Pubmed: 15516537.

134. Chiò A, Mora G, Leone M, et al. Piemonte and Valle d'Aosta Register for ALS (PARALS). Early symptom progression rate is related to ALS outcome: a prospective population-based study. Neurology. 2002; 59(1): 99-103, doi: 10.1212/wnl.59.1.99, indexed in Pubmed: 12105314.

135. Lyall RA, Donaldson N, Fleming T, et al. A prospective study of quality of life in ALS patients treated with noninvasive ventilation. Neurology. 2001; 57(1): 153-156, doi: 10.1212/wnl.57.1.153, indexed in Pubmed: 11445650.

136. Bourke SC, Bullock RE, Williams TL, et al. Noninvasive ventilation in ALS: indications and effect on quality of life. Neurology. 2003; 61(2): 171-177, doi: 10.1212/01.wnl.0000076182.13137.38, indexed in Pubmed: 12874394.

137. Hein $\mathrm{H}$, Schucher B, Magnussen $H$. Intermittierende Selbstbeatmung bei neuromuskulären Erkrankungen: Verlauf und Lebensqualität [Intermittent assisted ventilation in neuromuscular diseases: course and quality of life]. Pneumologie. 1999; 53(Suppl 2): S89-S90. 